\title{
Trabalho decente e vulnerabilidade ocupacional no Brasil *
}

\author{
Marcelo Weishaupt Proni ${ }^{* *}$
}

\begin{abstract}
Resumo
O principal desafio das políticas destinadas a promover o trabalho decente é a redução da vulnerabilidade ocupacional. No Brasil, apesar das iniciativas para reduzir o desemprego, combater o trabalho precário e erradicar as situações mais graves de exclusão e discriminação, permanece muito elevada a proporção de trabalhadores sem emprego regular e/ou expostos a uma inserção ocupacional inadequada. $\mathrm{O}$ artigo pretende: (i) apresentar a agenda de políticas sugeridas pela OIT para a promoção do trabalho decente e o combate a distintas formas de vulnerabilidade ocupacional; (ii) verificar se a retomada do crescimento econômico (2004-2008) produziu redução significativa no déficit de oportunidades de emprego e na proporção de situações ocupacionais mais precárias no País; e (iii) examinar as principais situações vulneráveis que afligiam os trabalhadores brasileiros após a crise econômica ocorrida entre o final de 2008 e meados de 2009. Dessa forma, procura-se ressaltar a importância de sustentar um crescimento econômico robusto e, ao mesmo tempo, eliminar a cultura da informalidade.
\end{abstract}

Palavras-chave: Trabalho decente; Trabalho precário; Trabalho informal;

\section{Abstract \\ Decent work and occupational vulnerability in Brazil}

The main challenge of the "decent work agenda" is the reduction of occupational vulnerability. In Brazil, despite efforts to reduce unemployment, to fight the precarious work and eradicate the most serious situations of exclusion and discrimination, the proportions of workers without regular job and/or exposed to a very precarious occupational insertion remain very high. The article aims to: (i) present the policy agenda suggested by the ILO to promote decent work and fighting various forms of occupational vulnerability; (ii) verify if the economic recovery (2004-2008) produced a significant reduction in the job opportunities deficit and in the proportion of precarious works in the country; and (iii) examine the main types of vulnerability among Brazilian workers after the economic crises that occurred between late 2008 and mid 2009. In addition, we intend to highlight the importance of sustaining robust economic growth and, at the same time, eliminate the culture of informality.

Keywords: Decent work; Precarious work; Informal work.

JEL J010, J210, J800.

\section{Introdução}

No ano 2000, a Organização das Nações Unidas divulgou a Declaração do Milênio, na qual estipula oito grandes objetivos (com metas específicas em cada um) para inspirar a adoção de políticas de desenvolvimento social nos países

\footnotetext{
* Trabalho recebido em 16 de maio de 2011 e aprovado em 8 de abril de 2012.

** Diretor Associado do Instituto de Economia da Universidade Estadual de Campinas (IE/Unicamp), Campinas, SP, Brasil. E-mail: mwproni@eco.unicamp.br.
} 
membros, em especial nas áreas mais pobres do globo, e aglutinar esforços no sentido de avançar substantivamente na construção de um mundo melhor até 2015. Inicialmente, a questão do emprego não foi ressaltada na definição das metas prioritárias. Posteriormente, em 2005, uma nova meta foi incluída no âmbito do primeiro objetivo (a erradicação da pobreza extrema e da fome), a saber: assegurar o emprego pleno e a possibilidade para todos, incluindo mulheres e jovens, de encontrar trabalho decente e produtivo.

Em 2010, a ONU fez um balanço dos avanços alcançados em cada meta estipulada. Na América Latina, observando o período 1998-2008, houve um pequeno incremento na proporção de pessoas empregadas (58\% para $61 \%$ ), uma redução na porcentagem de pessoas trabalhando por conta própria ou em negócios familiares (35\% para $31 \%$ ) e uma redução significativa na parcela classificada como "trabalhador pobre" (working poor), ou seja, os que pertencem a famílias com renda per capita inferior a US\$ 1,25 por dia (13\% para 7\%). Porém, em 2009, a crise econômica afetou negativamente o mercado de trabalho na região e elevou a proporção de trabalhadores desempregados ou em situação ocupacional muito vulnerável, interrompendo - ao menos momentaneamente - a tendência de diminuição da pobreza extrema (Naciones Unidas, 2010).

Alinhada com as diretrizes estabelecidas pela ONU, a Organização Internacional do Trabalho (OIT) produziu vários estudos ao longo da década, procurando dimensionar os problemas mais graves que afetam os trabalhadores em cada continente, examinar as diferenças intra-regionais e ressaltar a importância da adoção de agendas políticas nacionais dirigidas para a promoção do "trabalho decente" (decent work) e o combate à discriminação. Na América Latina, como produto de tal mobilização, foi proposta uma agenda democrática para soldar compromissos e nortear as ações dos governos nacionais no período 2006-2015, com metas de redução do déficit de trabalho decente em suas várias dimensões (OIT, 2006).

No Brasil, é inegável o sucesso dos esforços no sentido de alcançar o primeiro dos grandes objetivos de desenvolvimento do milênio: as metas específicas de reduzir pela metade a pobreza absoluta e a porcentagem da população que passa fome já foram superadas com folga, e há a expectativa de que o País estará próximo de eliminar os dois problemas em 2015. Porém, a terceira meta - que pode ser entendida de forma simplificada como uma diminuição expressiva das situações de desemprego e de alta precariedade ocupacional persiste sendo um grande desafio pelas características do mercado de trabalho nacional.

Muitos estudos já constataram que o desemprego, os baixos salários, a informalidade e a falta de proteção são problemas graves que afetam parcela significativa dos trabalhadores brasileiros. Durante a década de 1990 e início dos anos 2000, a condução da política econômica contribuiu para uma deterioração do 
mercado de trabalho nacional, um aumento do número de trabalhadores em situação muito precária e o surgimento de novas formas de informalidade (Antunes, 2006, Krein; Proni, 2010). Até 2003, portanto, predominaram tendências muito desfavoráveis aos trabalhadores: persistência de altas taxas de desemprego, expansão do trabalho informal e queda dos rendimentos médios. Contudo, a partir de 2004, começaram a ser verificados sinais claros de melhorias: redução do desemprego, aumento do emprego formal, recuperação do salário médio e redução da desigualdade na distribuição de renda (Cacciamali, 2010). De fato, a trajetória da economia brasileira até 2008 oferecia condições para uma gradual superação daqueles problemas crônicos em razão da dinâmica do emprego e da valorização do salário mínimo legal, assim como da maior eficácia das políticas de emprego e da regulação do trabalho (Baltar et al., 2010).

Este artigo não pretende fazer um exame exaustivo de todas as questões pertinentes que compõem esse campo de estudo, mas oferecer algumas indicações para pensar o tamanho do desafio de promover o trabalho decente por meio da redução do desemprego e do trabalho precário no Brasil. O foco da análise é o exame de dois aspectos dessa problemática: a insuficiência na geração de empregos e o estoque de ocupações informais claramente precárias. Para tal, é priorizada a dimensão quantitativa de distintas formas de vulnerabilidade ocupacional: o desemprego de longa duração, as atividades laborais não remuneradas e os postos de trabalho com baixos rendimentos e sem a cobertura da previdência social.

Mais especificamente, pretende-se verificar se, durante o período de retomada do dinamismo econômico (2004-2008), houve redução significativa no déficit de oportunidades de trabalho remunerado e na proporção de situações precárias, assim como examinar se a crise econômica ocorrida entre o último trimestre de 2008 e o primeiro semestre de 2009 agravou o problema do desemprego e da precariedade ocupacional no País. Dessa forma, o artigo pretende contribuir para o atual debate sobre as políticas necessárias para a ampliação dos empregos "dignos" (pelo menos em relação ao rendimento mensal e à proteção social), ressaltando a importância dos efeitos benéficos proporcionados pelo dinamismo econômico e pela regulação pública do trabalho.

A argumentação está dividida em cinco seções, além desta introdução e as considerações finais. Na próxima seção, é feita uma breve apresentação da agenda de políticas sugeridas pela OIT para a promoção do "trabalho decente" e o combate a distintas formas de vulnerabilidade no mercado de trabalho. Em seguida, são mencionados dois estudos que procuraram oferecer uma visão multidimensional do trabalho decente no Brasil. Na terceira seção, a análise se concentra nas melhorias observadas na estrutura ocupacional brasileira entre 2003 e 2008, antes da crise econômica. Então, o foco se desloca para a mensuração das principais situações de vulnerabilidade ocupacional em 2008 e em 2009. Ao final, são acrescentadas considerações que reforçam a importância de combater a informalidade no País. 


\section{Promoção do trabalho decente: estratégia de combate à precariedade ocupacional}

As profundas transformações econômicas trazidas pelo avanço da globalização, pela reestruturação produtiva de grandes empresas e pela adoção de políticas macroeconômicas focadas na estabilização monetária tiveram consequências negativas sobre o mercado de trabalho tanto nos países desenvolvidos como naqueles em desenvolvimento. Num contexto dominado pela ideologia neoliberal, a OIT tinha dificuldades para defender recomendações em prol da promoção de melhorias substantivas nas relações e nas condições de trabalho. Ao final da década de 1990, em oposição ao discurso conformista a respeito da inevitabilidade de um "crescimento sem emprego" - em geral associado à introdução de inovações tecnológicas e organizacionais -, a instituição renovou seu compromisso com a adoção de políticas para a geração de trabalho e renda, assim como para a difusão dos direitos do trabalho, em particular nos países economicamente mais atrasados (OIT, 1999). E, no início da década seguinte, diferenciando-se do discurso corrente em favor da flexibilidade das relações de trabalho - que procurava legitimar a difusão de novos tipos de informalidade e a redução do custo do trabalho -, a OIT lançou uma campanha internacional pela promoção do trabalho decente, reafirmando que o trabalho não pode ser entendido como mero fator de produção e que este mercado tão singular não pode ser autorregulado. Tendo como prerrogativa a afirmação do papel do Estado democrático na consolidação de um padrão civilizado de relações sociais, o discurso da OIT baseou-se no pressuposto de que o trabalho continua sendo a via fundamental para a superação da pobreza e a inclusão social, condição básica para uma vida digna e para o exercício da cidadania (ILO, 2002).

O importante a reter é que foi num contexto de crise global do emprego, com sinais evidentes de deterioração generalizada das condições de trabalho e com a pressão do discurso neoliberal contra os sistemas públicos de proteção social que, em 2003, a OIT propôs a adoção de uma Agenda de Trabalho Decente (OIT, 2004). Essa Agenda expressa uma estratégia diversificada de enfrentamento de situações de precariedade e ameaças aos trabalhadores na qual a OIT procura estabelecer parcerias com governos nacionais para a criação de políticas e a implantação de programas destinados a propiciar trabalho em condições dignas e em quantidade suficiente para todos, tanto no meio urbano como no meio rural (Abramo; Bolzón; Ramos, 2008).

A expressão decent work $^{1}$ tem a vantagem de ser suficientemente genérica para ser aplicada a diferentes contextos nacionais e de ser adequadamente específica para enfatizar as prioridades fundamentais de uma agenda política nesse

(1) Além de "decent work", a literatura internacional especializada também utiliza o termo "decent employment" (Ocampo, 2007), procurando enfatizar uma relação de assalariamento subordinada a um conjunto de normas estipuladas por intermédio de legislação trabalhista ou acordos coletivos. 
campo. Trata-se de colocar, como objetivo prioritário, a difusão de padrões de emprego que sejam caracterizados por um trabalho devidamente remunerado e capaz de garantir uma vida digna, exercido em condições de liberdade, equidade e segurança, com ênfase no respeito às normas internacionais do trabalho (em especial, a eliminação de todas as formas de trabalho forçado, a abolição efetiva do trabalho infantil e o combate sistemático às distintas formas de discriminação em matéria de emprego e ocupação). Ressalte-se, ainda, que a promoção de empregos dessa qualidade também está associada à extensão da proteção social e ao fortalecimento do diálogo entre empresas, sindicatos e governo (OIT, 2006). Nesse sentido, percebe-se que já não basta combater a informalidade apenas pela formalização do contrato de trabalho, sendo necessário garantir um patamar mínimo de direitos sociais e estimular a democratização das relações de trabalho.

Essa proposição genérica da OIT começou, então, a ser aplicada de maneira tímida na maioria dos países que adotaram a Agenda, inclusive na América Latina. Pode-se dizer que, inicialmente, as políticas implementadas tiveram alcance muito limitado, ou sequer foram adotadas em alguns países da região. Um compromisso mais consistente só foi percebido após a XVI Reunião Regional Americana da OIT, realizada em maio de 2006, em Brasília, quando foi divulgado o documento Trabalho decente nas Américas: uma agenda hemisférica 2006-2015. As principais políticas recomendadas no documento, com seus respectivos objetivos e metas para o período 2006-2015, estão sintetizadas no Quadro 1. Evidentemente, cada país tem autonomia na condução e avaliação dos programas.

É importante mencionar que, em 2006, as tendências do mercado de trabalho na América Latina justificavam o tom otimista da Agenda. Antes da crise financeira que atingiu a região no final de 2008, os indicadores sobre a evolução do mercado de trabalho mostravam tendências favoráveis - ainda que as melhorias fossem graduais e se concentrassem nas áreas mais dinâmicas -, em grande medida decorrentes do crescimento econômico e de políticas governamentais para combater a informalidade e para elevar o salário mínimo. De acordo com estudo da Cepal (2009), no quinquênio 2004-2008, a América Latina registrou altas taxas de expansão econômica (as mais elevadas em 40 anos), o que teve efeitos positivos na geração de empregos ${ }^{2}$. Por sua vez, os três pilares da institucionalidade trabalhista (isto é, a regulação das relações individuais e coletivas de trabalho, a proteção contra o desemprego e as políticas ativas do mercado de trabalho) também desempenharam papel fundamental, uma vez que influenciaram na quantidade e na qualidade dos postos de trabalho gerados (Weller, 2009).

(2) É importante notar que, nos últimos anos, a Comissão Econômica para a América Latina e o Caribe (Cepal) recuperou o espírito crítico em relação ao modelo excludente de desenvolvimento econômico e voltou a considerar o combate à desigualdade social como um dos temas centrais da agenda política na região, recolocando as análises da dinâmica do emprego, da estrutura ocupacional e da produtividade do trabalho como fundamentos para a compreensão da distribuição de renda (Cepal, 2010). 

Quadro 1

Agenda de políticas gerais para a promoção do trabalho decente proposta pela OIT

\begin{tabular}{|c|c|c|}
\hline Políticas & Objetivos & Metas \\
\hline $\begin{array}{l}\text { 1. Crescimento econômico } \\
\text { promotor do emprego }\end{array}$ & $\begin{array}{l}\text { A geração de mais oportunidades de } \\
\text { emprego deve ser considerada } \\
\text { objetivo central da política } \\
\text { econômica. }\end{array}$ & $\begin{array}{l}\text { Assegurar um crescimento econômico de, pelo menos, } 5 \% \text { ao ano nos próximos } 10 \\
\text { anos, de maneira sustentada e não flutuante, como condição necessária para reduzir } \\
\text { significativamente o atual déficit de trabalho decente. }\end{array}$ \\
\hline $\begin{array}{l}\text { 2. Respeito efetivo aos princípios } \\
\text { e direitos fundamentais no } \\
\text { trabalho }\end{array}$ & $\begin{array}{l}\text { Assegurar o respeito efetivo aos } \\
\text { princípios e direitos fundamentais no } \\
\text { trabalho. }\end{array}$ & $\begin{array}{l}\text { Os direitos fundamentais no trabalho constituem um corpo mínimo e } \\
\text { universalmente aceito de direitos do trabalho incorporados às respectivas } \\
\text { legislações nacionais e à cultura do trabalho dos diferentes países da região. }\end{array}$ \\
\hline a) Trabalho infantil & $\begin{array}{l}\text { Eliminação progressiva do trabalho } \\
\text { infantil. }\end{array}$ & $\begin{array}{l}\text { 1. Eliminar as piores formas de trabalho infantil num prazo de } 10 \text { anos (2015). } \\
\text { 2. Eliminar o trabalho infantil em sua totalidade em um prazo de } 15 \text { anos (2020). }\end{array}$ \\
\hline b) Trabalho forçado & $\begin{array}{l}\text { Eliminação progressiva do trabalho } \\
\text { forçado. }\end{array}$ & $\begin{array}{l}\text { Em um prazo de } 10 \text { anos, reduzir entre } 20 \% \text { e } 35 \% \text { o número de trabalhadores em } \\
\text { regime de trabalho forçado. }\end{array}$ \\
\hline $\begin{array}{l}\text { c) Liberdade sindical e } \\
\text { negociação coletiva }\end{array}$ & $\begin{array}{l}\text { Melhorar o cumprimento dos direitos } \\
\text { fundamentais por meio de avanços na } \\
\text { garantia dos diferentes elementos da } \\
\text { liberdade sindical, em particular a não } \\
\text { discriminação sindical, otimizando a } \\
\text { cobertura da negociação coletiva e } \\
\text { ampliando seus conteúdos. }\end{array}$ & $\begin{array}{l}\text { Dotar as legislações de melhores elementos de proteção sindical, em especial de } \\
\text { procedimentos e recursos administrativos e judiciais efetivos e rápidos para o caso } \\
\text { de violações desses direitos, melhorando também a qualidade dos acordos e } \\
\text { convênios, tanto com relação ao número de trabalhadores cobertos (com um } \\
\text { aumento de } 10 \% \text {, ao menos, em nível nacional) como à ampliação de seus } \\
\text { conteúdos (por exemplo, incluindo cláusulas sobre produtividade) e à solução } \\
\text { autônoma de conflitos. }\end{array}$ \\
\hline $\begin{array}{l}\text { d) Não discriminação e } \\
\text { igualdade no trabalho }\end{array}$ & $\begin{array}{l}\text { Eliminar progressivamente os } \\
\text { mecanismos de discriminação } \\
\text { existentes no mercado de trabalho. }\end{array}$ & $\begin{array}{l}\text { Reduzir em } 50 \% \text { os índices de segregação e as desigualdades de rendimento por } \\
\text { gênero e origem étnico-racial (com relação aos níveis atuais) em um prazo de } 10 \\
\text { anos. }\end{array}$ \\
\hline $\begin{array}{l}\text { 3. Maior eficiência e abrangência } \\
\text { da proteção social }\end{array}$ & $\begin{array}{l}\text { Ampliar e fortalecer os diferentes } \\
\text { sistemas de proteção social dos } \\
\text { trabalhadores. }\end{array}$ & Em um prazo de 10 anos, incrementar em $20 \%$ a cobertura da proteção social. \\
\hline 4. Diálogo social efetivo & $\begin{array}{l}\text { Promover a institucionalização do } \\
\text { diálogo social em bases voluntárias. }\end{array}$ & $\begin{array}{l}\text { Estimular que todos os países da região realizem ações para fortalecer o diálogo } \\
\text { social e que em um prazo máximo de } 10 \text { anos contem com espaços de diálogo } \\
\text { social institucionalizados, sustentáveis em bases voluntárias. }\end{array}$ \\
\hline
\end{tabular}

Fonte: OIT. Trabalho decente nas Américas, cap. 4. 

Além de redução do desemprego aberto e paulatina recuperação dos rendimentos do trabalho, em alguns países da região havia evidências de diminuição nas formas de trabalho degradantes, assim como de incremento nas ações de combate sistemático à desigualdade e à discriminação. Embora se mantivesse a enorme assimetria entre as situações nacionais e permanecesse bastante elevado o estoque de problemas estruturais a serem enfrentados, difundiuse a opinião de que as situações de maior privação e vulnerabilidade ocupacional estavam se reduzindo. Contudo, a forte crise internacional - cujos efeitos se manifestaram intensamente no primeiro semestre de 2009 - ameaçou reverter os avanços conseguidos na América Latina no que se refere à estruturação do mercado de trabalho e à luta contra a pobreza. Ainda que o prazo estipulado para as metas não seja cumprido, foi reforçada a importância da Agenda proposta pela OIT para os países em desenvolvimento, e espera-se que tais políticas sejam adotadas integralmente pelos governos nacionais (OIT, 2009a).

No Brasil, as primeiras iniciativas com essa rubrica começaram em junho de 2003 quando o governo federal e a OIT assinaram um Memorando de Entendimento. Os esforços iniciais ficaram restritos à adoção de um conjunto de ações compensatórias ou de impacto geralmente circunscrito aos segmentos expostos a uma privação extrema (em especial o desemprego crônico) ou a uma elevada precariedade ocupacional (cujo principal indicador é a insuficiência de renda) ${ }^{3}$. Em 2006, foi definida a Agenda Nacional de Trabalho Decente (Brasil. MTE, 2006). Pode-se dizer que houve uma convergência entre tal Agenda e as prioridades do governo Lula no campo social: foram implementadas ações para melhorar o padrão de emprego (valorização do salário mínimo e formalização do contrato de trabalho), foram reestruturados os programas de proteção aos trabalhadores (com especial atenção para os grupos mais vulneráveis) e foram ampliados os programas sociais voltados para o combate à miséria (tais como o Fome Zero e o Bolsa Família). Mas, não é tarefa simples a mensuração dos avanços na promoção do trabalho decente e no combate à precariedade ocupacional (Proni; Rocha, 2010).

\section{Diagnósticos sobre o trabalho decente no Brasil}

No início da década, o Escritório Regional da OIT para a América Latina e o Caribe realizou um primeiro estudo para avaliar o nível de desenvolvimento do trabalho decente em 15 países da região (que foi definido em função de variações

(3) Até 2003, vinha se agravando o problema da informalidade e vinham se enfraquecendo os segmentos mais organizados dos trabalhadores urbanos. Por sua vez, o foco das políticas governamentais se concentrava no enfrentamento pontual de questões politicamente urgentes, como o combate ao desemprego aberto, ao passo que não havia preocupação relevante com a elevação da qualidade dos empregos, assim como eram muito pouco eficientes os programas de erradicação das formas mais degradantes de trabalho. 
positivas ou negativas em sete quesitos, num período de tempo delimitado, que indicavam avanço, retrocesso ou estancamento). Esse estudo priorizou a situação do emprego e da proteção social para os trabalhadores e procurou colocar em evidência o desempenho do mercado de trabalho latino-americano entre $1990 \mathrm{e}$ 2000, em particular no que se refere à taxa de desemprego, ao peso da informalidade, ao salário industrial, ao salário mínimo, ao número de horas trabalhadas, à defasagem entre os rendimentos médios de homens e mulheres, assim como em relação à cobertura da previdência social (OIT, 2001).

A metodologia utilizada foi depois abandonada ${ }^{4}$, mas o estudo foi importante para indicar aqueles países que registraram avanços nas condições de trabalho decente durante a década de 1990 (Chile, Colômbia, Costa Rica, El Salvador, Honduras, Panamá e Paraguai), aqueles onde a situação permaneceu constante (Bolívia e Peru) e aqueles onde foi registrado algum retrocesso (Argentina, Brasil, Equador, México, Uruguai e Venezuela). De qualquer modo, em 2000, o índice brasileiro refletia uma situação geral melhor do que na maioria dos países latino-americanos. Desde então, vários esforços foram feitos, na América Latina, no sentido de aprimorar os instrumentos de mensuração do grau de desenvolvimento nacional em termos de trabalho decente. Em razão das especificidades nacionais, foram elaboradas diferentes metodologias para mensurar os déficits de trabalho decente e analisar suas tendências.

No Brasil, foram realizados dois estudos que constituem referência obrigatória para o diagnóstico dos problemas e avanços nessa área e para a construção de uma metodologia apropriada aos sistemas de informações disponíveis. Em 2008, a Cepal, o PNUD e a OIT divulgaram um estudo detalhado sobre a situação do emprego, do desenvolvimento humano e do trabalho decente, mostrando a redução das precariedades no mercado de trabalho e das assimetrias relacionadas com gênero e raça no período 1992-2006. Esse documento possibilitou uma primeira avaliação dos resultados das políticas de promoção do trabalho decente que vinham sendo implementadas no País.

De acordo com esse estudo, com a inflexão nas tendências do mercado de trabalho nacional na década atual - com destaque para a queda na taxa de desemprego aberto, a geração de empregos formais, a redução do peso da informalidade, a reversão da trajetória de queda dos rendimentos do trabalho e a retomada do emprego na grande empresa - houve uma melhoria significativa em vários aspectos considerados pelas metodologias aqui mencionadas, o que

(4) Estudos posteriores da OIT sobre a situação do trabalho decente, ao procurarem mensurar os déficits ou carências registrados, priorizam quatro dimensões de análise: lacunas na legislação, déficits na geração de emprego e renda, falta de cobertura na proteção social e restrições à negociação coletiva (Proni; Rocha, 2010). Tais estudos geralmente dão preferência a utilizar o termo no plural - déficits - e não no singular, sem a pretensão de elaborar um indicador sintético único (Abramo; Sanches; Costanzi, 2008). 
comprova a importância da recuperação do crescimento econômico e da política de elevação do salário mínimo. Apesar disso, o País ainda convivia com um mercado de trabalho estruturalmente segmentado, que excluía social e economicamente uma parcela expressiva de trabalhadores, gerando elevados déficits de trabalho decente.

A metodologia desenvolvida baseou-se numa abordagem multidimensional, com quatro áreas temáticas (emprego, proteção social, direitos no trabalho e diálogo social) e ainda num eixo transversal para examinar a questão da desigualdade de gênero e de raça. Em cada área ou eixo há várias dimensões (aspectos) às quais correspondem um ou mais indicadores, totalizando 28 indicadores quantitativos (Cepal/PNUD/OIT, 2008). Não houve a preocupação de apresentar um gráfico sintético por eixo, muito menos de criar um índice global. Em vez disso, uma novidade do estudo foi a iniciativa de compatibilizar a análise da evolução dos indicadores de trabalho decente com o acompanhamento do índice de desenvolvimento humano (IDH).

O relatório também destaca outros aspectos que merecem atenção: i) as desigualdades raciais e de gênero no mercado de trabalho permaneciam bastante altas e continuavam alimentando a desigualdade social (os rendimentos médios das mulheres eram 30\% inferiores aos dos homens, e os dos negros eram $47 \%$ inferiores aos dos brancos); ii) outro déficit importante é a pequena proporção (apenas metade) de ocupados que contribuía para a Previdência Social, ainda que o aumento da ocupação formal sugerisse uma tendência de melhoria nesse indicador; iii) significativos avanços foram registrados no combate ao trabalho infantil e ao trabalho forçado, embora ainda houvesse muito a ser feito nessa área; e iv) houve, nos últimos anos, um crescimento das taxas de sindicalização (maior entre as mulheres, especialmente as negras) e da efetividade dos resultados das negociações coletivas (Cepal/PNUD/OIT, 2008, p. 72).

O estudo mais recente e mais completo sobre o progresso registrado na década de 2000 em matéria de trabalho decente no Brasil foi publicado em 2009. O Perfil do trabalho decente no Brasil priorizou indicadores referentes à população com 16 anos ou mais de idade (com exceção do trabalho infantil), delimitando a análise ao período 1992-2007. Foram consideradas dez dimensões de análise, a saber: 1) oportunidades de emprego, 2) rendimentos adequados e trabalho produtivo, 3) jornada de trabalho decente, 4) combinação entre trabalho, vida pessoal e vida familiar, 5) trabalho a ser abolido, 6) estabilidade e segurança no trabalho, 7) igualdade de oportunidades e de tratamento no emprego, 8) ambiente de trabalho seguro, 9) seguridade social, 10) diálogo social e representação de trabalhadores e empregadores.

É importante explicar que esse modelo de análise foi elaborado com a intenção de oferecer um instrumento de monitoramento e avaliação anual. Cada 
dimensão contempla uma variedade de indicadores quantitativos (sobre a evolução dos temas relevantes para os quais há informação), assim como indicadores normativos (sobre o conteúdo e a efetividade da legislação ou política em vigor e sobre a ratificação de convenções da OIT).

Por exemplo, a primeira dimensão (oportunidades de emprego) é examinada a partir dos seguintes indicadores: taxa de participação, taxa de ocupação, taxa de desemprego, taxa de formalidade, proporção de jovens que não estudam nem trabalham, taxa de desemprego juvenil. Em acréscimo, são considerados como indicadores normativos: a) compromisso com o pleno emprego e b) seguro-desemprego.

No caso da segunda dimensão (rendimentos adequados e trabalho produtivo), são elencados os seguintes indicadores: porcentagem de trabalhadores pobres e miseráveis (de acordo com a renda familiar per capita), renda média mensal do trabalho principal, proporção de trabalhadores que ganham abaixo de 2/3 do rendimento mediano real, porcentagem de trabalhadores não remunerados, evolução do salário mínimo real. O indicador normativo diz respeito ao salário mínimo legal.

A conclusão mais geral do documento é que: i) vários déficits de trabalho decente no Brasil vêm se reduzindo, com destaque para o declínio do trabalho infantil, a diminuição da proporção de empregados sem o vínculo formalizado e a redução do percentual de trabalhadores idosos sem aposentadoria ou pensão; porém, ii) muitos desafios ainda são bastante persistentes, em especial as discrepâncias salariais entre homens e mulheres e entre brancos e negros, assim como o elevado número de jovens que não trabalham nem estudam e a existência de trabalho forçado. Além disso, o relatório também destaca as altas taxas de desemprego aberto e de informalidade, que aumentaram durante a década de 1990 e começaram a declinar a partir de 2004. Obviamente, não há espaço aqui para apresentar todos os resultados desse estudo, mas fica evidente a intenção de ressaltar os "progressos encorajadores" que foram alcançados e pontuar as questões prioritárias que merecem atenção das políticas públicas (OIT, 2009b, p. iv).

Em suma, os diagnósticos realizados mapearam os principais problemas na geração de empregos e na qualidade dos postos de trabalho, explicitaram os tipos de precariedade ocupacional a que estão submetidos os grupos mais vulneráveis e ressaltaram as desigualdades por sexo e raça ${ }^{5}$. Procurando contribuir nessa direção, a seguir serão descritas algumas mudanças relevantes verificadas no mercado de trabalho brasileiro num contexto de razoável dinamismo econômico para destacar a dimensão dos problemas mais graves em termos de falta de oportunidades e trabalho precário, colocando em evidência algumas tendências.

(5) Esse diagnóstico tem sido atualizado anualmente pelo escritório da OIT no Brasil (Berg; Ribeiro, 2010). 


\section{Melhorias no mercado de trabalho brasileiro no período 2003-2008}

Este artigo não tem a pretensão de mensurar os déficits de trabalho decente no Brasil, o que exigiria computar todas as situações que contradizem os critérios definidos pela OIT nos quatro eixos norteadores, reunindo uma gama de indicadores nas dez dimensões de análise, como explicado anteriormente. A prerrogativa nesta seção é verificar a hipótese de que a evolução positiva da economia brasileira entre setembro de 2003 e setembro de 2008, associada com distintas políticas do governo federal, produziu melhorias significativas em termos da redução das situações mais evidentes de privação e de precariedade no trabalho, em particular no que se refere à insuficiência na geração de empregos, à informalidade, aos baixos rendimentos e à falta de cobertura da seguridade social.

Entre 2003 e 2008, de acordo com o IBGE, a população economicamente ativa cresceu em quase 10 milhões de pessoas no Brasil (Tabela 1). As informações da PNAD permitem estimar que houve uma redução significativa no número de desempregados (de 9,4 para 7,7 milhões de pessoas) e um aumento expressivo dos ocupados com remuneração (11,8 milhões). Por outro lado, foi pequena a redução no número de ocupados sem rendimento monetário (de 7,6 para 7,2 milhões). De qualquer forma, em 2008, ainda havia quase 15 milhões de brasileiros que estavam privados de uma ocupação que propiciasse alguma remuneração. E nota-se que os trabalhadores em atividades que se desenvolvem à margem de relações mercantis (ou seja, produção para o próprio consumo e construção para uso próprio) somavam 3,8 milhões de pessoas, enquanto outros 3,5 milhões estavam ocupados em trabalhos não remunerados (a maioria em atividades agrícolas).

Tabela 1

População economicamente ativa (PEA), ocupados (com e sem remuneração) e desempregados Brasil: 2003 e 2008

\begin{tabular}{lrrrrrr}
\hline \multirow{2}{*}{ Condição de Atividade } & \multicolumn{2}{c}{2003} & \multicolumn{2}{c}{2008} & \multicolumn{2}{c}{$2008-2003$} \\
\cline { 2 - 6 } & $(1.000)$ & $(\%)$ & $(1.000)$ & $(\%)$ & $(1.000)$ & $(\%)$ \\
\hline PEA (16 anos ou mais) ${ }^{(1)}$ & 86.968 & 100,0 & 96.749 & 100,0 & 9.781 & 11,2 \\
Desempregados (2) & 9.351 & 10,8 & 7.718 & 8,0 & -1.633 & $-17,5$ \\
Pessoas ocupadas & 77.617 & 89,2 & 89.031 & 92,0 & 11.414 & 14,7 \\
Ocupados com remuneração monetária & 70.039 & 80,5 & 81.794 & 84,5 & 11.756 & 16,8 \\
Ocupados sem remuneração monetária & 7.579 & 8,7 & 7.237 & 7,5 & -342 & $-4,5$ \\
- Trabalho não remunerado & 4.344 & 5,0 & 3.464 & 3,6 & -880 & $-20,2$ \\
- Produção para consumo próprio & 3.128 & 3,6 & 3.678 & 3,8 & 551 & 17,6 \\
- Trab. na construção para uso próprio & 108 & 0,1 & 94 & 0,1 & -13 & $-12,3$ \\
\hline
\end{tabular}

Notas: ${ }^{(1)}$ Exclui a população residente na área rural da Região Norte, exceto Tocantins. entrevista.

(2) População de 16 anos ou mais que procurou trabalho num período de 30 dias antes da

Fonte: IBGE - PNAD. 
Tabela 2

População de 10 a 15 anos de idade ocupada (com e sem remuneração) ou procurando trabalho Brasil: 2003 e 2008

\begin{tabular}{lrrrrrr}
\hline \multirow{2}{*}{ Condição de Atividade } & \multicolumn{2}{c}{2003} & \multicolumn{2}{c}{2008} & \multicolumn{2}{c}{$2008-2003$} \\
\cline { 2 - 7 } & $(1.000)$ & $(\%)$ & $(1.000)$ & $(\%)$ & $(1.000)$ & $(\%)$ \\
\hline PEA (10 a 15 anos) ${ }^{(1)}$ & 3.000 & 100,0 & 2.283 & 100,0 & -717 & $-23,9$ \\
Desempregados ${ }^{(2)}$ & 470 & 15,7 & 379 & 16,6 & -91 & $-19,3$ \\
Pessoas ocupadas & 2.530 & 84,3 & 1.904 & 83,4 & -626 & $-24,7$ \\
Ocupados com remuneração monetária & 934 & 31,1 & 840 & 36,8 & -94 & $-10,1$ \\
Ocupados sem remuneração monetária & 1.596 & 53,2 & 1.064 & 46,6 & -532 & $-33,3$ \\
- Trabalho não remunerado & 1.347 & 44,9 & 811 & 35,5 & -536 & $-39,8$ \\
- Produção para consumo próprio & 240 & 8,0 & 241 & 10,5 & 1 & 0,6 \\
- Trab. na construção para uso próprio & 10 & 0,3 & 12 & 0,5 & 2 & 25,5 \\
\hline
\end{tabular}

Notas: ${ }^{(1)}$ Exclui a população residente na área rural da Região Norte, exceto Tocantins.

(2) População de 10 a 15 anos que procurou trabalho num período de 30 dias antes da entrevista.

Fonte: IBGE - PNAD.

Embora a legislação brasileira estabeleça em 16 anos a idade mínima para começar a trabalhar, o "trabalho infantil"" ainda é muito frequente entre as famílias de baixa renda, especialmente na agricultura familiar. Observando a população com idade entre 10 e 15 anos no Brasil (Tabela 2), houve uma diminuição importante da população economicamente ativa (de 3 para 2,3 milhões) entre 2003 e 2008 e redução no número de crianças procurando trabalho (de 470 mil para 380 mil). Por outro lado, chama atenção a redução muito significativa no número de ocupados sem remuneração monetária (de 1,6 para 1,1 milhão) e o fato de estes serem em maior número que os ocupados com remuneração (840 mil - dos quais 568 mil eram empregados sem carteira, 149 mil eram trabalhadores domésticos e 123 mil trabalhavam por conta própria em 2008). Além disso, em contraposição à redução no número de ocupados em trabalho não remunerado, não houve alteração no número de trabalhadores na produção para o próprio consumo.

A Tabela 3 refere-se aos ocupados com idade superior a 15 anos que possuíam algum rendimento monetário. A PNAD indica que houve um aumento muito expressivo no número de empregados com carteira de trabalho assinada $(7,8$ milhões) e de funcionários públicos estatutários (1 milhão) entre 2003 e 2008. Mas, houve também aumento no número de empregados sem carteira assinada $(1,3$

(6) O Unicef define "trabalho infantil" como as atividades econômicas realizadas por crianças entre 5 e 11 anos de idade, assim como o trabalho de pré-adolescentes com idade entre 12 e 14 anos quando corresponde a uma jornada de, pelo menos, 14 horas por semana (ou 42 horas por semana, quando combinado com trabalho doméstico). No Brasil, a partir de 14 anos de idade, é aceita a condição de "aprendiz profissional”, mas são poucos os jovens trabalhadores entre 14 e 15 anos que se enquadram nesta condição. 
milhão), pequenos empregadores (740 mil), trabalhadores em serviços domésticos (460 mil) e trabalhadores por conta própria (360 mil).

Embora tenha se elevado a proporção de pessoas que tinham uma relação de emprego formalmente reconhecida (de $44 \%$ para $49 \%$ ), permanecia muito elevada a porcentagem daquelas trabalhando de forma independente ou submetida a uma relação de emprego inadequada. Em 2008, os empregados sem carteira assinada correspondiam a $18 \%$ desse conjunto e os trabalhadores em serviços domésticos sem registro de vínculo eram $6 \%$. E, não obstante tenha se reduzido a proporção de trabalhadores por conta própria, esta ainda correspondia a $22 \%$.

Tabela 3

Ocupados (16 anos ou mais de idade) com remuneração positiva, por posição na ocupação Brasil: 2003 e 2008

\begin{tabular}{lrrrrrr}
\hline \multirow{2}{*}{ Posição na Ocupação Principal } & \multicolumn{2}{c}{2003} & \multicolumn{2}{c}{2008} & \multicolumn{2}{c}{$2008-2003$} \\
\cline { 2 - 7 } & $(1.000)$ & $(\%)$ & $(1.000)$ & $(\%)$ & $(1.000)$ & $(\%)$ \\
\hline Militar & 254 & 0,4 & 262 & 0,3 & 8 & 3,1 \\
Funcionário público estatutário & 5.040 & 7,2 & 6.101 & 7,5 & 1.061 & 21,1 \\
Empregado com carteira assinada & 23.896 & 34,1 & 31.727 & 38,8 & 7.831 & 32,8 \\
Empregado sem carteira assinada & 13.787 & 19,7 & 15.080 & 18,4 & 1.294 & 9,4 \\
Trabalhador doméstico c/ carteira & 1.661 & 2,4 & 1.770 & 2,2 & 109 & 6,5 \\
Trabalhador doméstico s/ carteira & 4.309 & 6,2 & 4.658 & 5,7 & 349 & 8,1 \\
Trabalhador por conta própria & 17.736 & 25,3 & 18.099 & 22,1 & 363 & 2,0 \\
Empregador & 3.356 & 4,8 & 4.098 & 5,0 & 742 & 22,1 \\
\hline Ocupados com remuneração monetária & 70.039 & 100,0 & 81.794 & 100,0 & 11.756 & 16,8 \\
\hline
\end{tabular}

Fonte: IBGE - PNAD.

Feita esta rápida apresentação de mudanças na estrutura ocupacional brasileira no período examinado, cabe agora analisar as situações mais preocupantes de precariedade ocupacional da população com 16 anos ou mais de idade. Na Tabela 4, pode-se notar que cresceu o número de ocupados com remuneração positiva, mas que recebiam menos do que o salário mínimo legal (de 13,5 milhões em 2003 para 16,8 milhões em 2008). Ou seja, considerando o salário mínimo como um dos indicadores relevantes para classificar um trabalho como "legalmente aceitável", nota-se que houve um aumento em termos absolutos do número de trabalhadores em situação precária nesse período. Mas, também convém esclarecer que o peso dos ocupados com rendimento mensal menor que 1 s.m. no total dos ocupados remunerados não se alterou (19\% em 2003 e $20 \%$ em 2008).

$\mathrm{O}$ aumento mais expressivo desse tipo de precariedade ocupacional ocorreu entre os trabalhadores em serviços domésticos (1,6 milhão). Por outro lado, deve-se ressaltar o elevado número de trabalhadores por conta própria (ainda que a proporção tenha se reduzido um pouco) e de empregados sem carteira assinada, 
que juntos somavam mais de 13 milhões de pessoas em 2008 (78\% do total dos ocupados com remuneração inferior ao salário mínimo).

Portanto, excluindo situações regulares que podem estar associadas com uma jornada de trabalho parcial - empregados com carteira assinada, funcionários estatutários e militares ganhando menos de 1 s.m. -, a Tabela 4 permite mensurar uma das facetas da falta de acesso a empregos em acordo com as normas da legislação trabalhista vigente.

Tabela 4

Ocupados (16 anos ou mais de idade) com rendimento mensal menor que 1 s.m. nominal ${ }^{(1)}$ de acordo com a posição na ocupação

Brasil: 2003 e 2008

\begin{tabular}{lrrrrrr}
\hline \multirow{2}{*}{ Posição na Ocupação Principal } & \multicolumn{2}{c}{2003} & \multicolumn{2}{c}{2008} & \multicolumn{2}{c}{$2008-2003$} \\
\cline { 2 - 7 } & $(1.000)$ & $(\%)$ & $(1.000)$ & $(\%)$ & $(1.000)$ & $(\%)$ \\
\hline Militar & 24 & 0,2 & 5 & 0,0 & -19 & $-80,4$ \\
Funcionário público estatutário & 67 & 0,5 & 42 & 0,2 & -25 & $-37,4$ \\
Empregado com carteira assinada & 360 & 2,7 & 248 & 1,5 & -112 & $-31,2$ \\
Empregado sem carteira assinada & 4.724 & 35,0 & 5.723 & 34,1 & 999 & 21,2 \\
Trabalhador doméstico c/ carteira & 79 & 0,6 & 54 & 0,3 & -25 & $-32,1$ \\
Trabalhador doméstico s/ carteira & 1.536 & 11,4 & 3.152 & 18,8 & 1.616 & 105,2 \\
Trabalhador por conta própria & 6.565 & 48,6 & 7.341 & 43,8 & 776 & 11,8 \\
Empregador & 147 & 1,1 & 205 & 1,2 & 57 & 38,1 \\
\hline Ocupados com remuneração < 1 s.m. & 13.504 & 100,0 & 16.769 & 100,0 & 3.265 & 24,2 \\
\hline
\end{tabular}

Nota: ${ }^{(1)}$ Considerando o valor do salário mínimo vigente em setembro de 2003 e em set. de 2008.

Fonte: IBGE - PNAD.

Tabela 5

Ocupados (16 anos ou mais) com rendimento mensal positivo e menor que 1 s.m. real ${ }^{(1)}$ de acordo com a posição na ocupação

Brasil: 2003 e 2008

\begin{tabular}{lrrrrrr}
\hline \multirow{2}{*}{ Posição na Ocupação Principal } & \multicolumn{2}{c}{2003} & \multicolumn{2}{c}{2008} & \multicolumn{2}{c}{$2008-2003$} \\
\cline { 2 - 7 } & $(1.000)$ & $(\%)$ & $(1.000)$ & $(\%)$ & $(1.000)$ & $(\%)$ \\
\hline Militar & 56 & 0,2 & 5 & 0,0 & -51 & $-91,7$ \\
Funcionário público estatutário & 881 & 2,9 & 42 & 0,2 & -839 & $-95,3$ \\
Empregado com carteira assinada & 6.065 & 19,7 & 248 & 1,5 & -5.817 & $-95,9$ \\
Empregado sem carteira assinada & 9.028 & 29,4 & 5.723 & 34,1 & -3.305 & $-36,6$ \\
Trabalhador doméstico c/ carteira & 1.055 & 3,4 & 54 & 0,3 & -1.001 & $-94,9$ \\
Trabalhador doméstico s/ carteira & 3.832 & 12,5 & 3.152 & 18,8 & -680 & $-17,8$ \\
Trabalhador por conta própria & 9.526 & 31,0 & 7.341 & 43,8 & -2.185 & $-22,9$ \\
Empregador & 310 & 1,0 & 205 & 1,2 & -105 & $-33,7$ \\
\hline Ocupados com remuneração < 1 s.m. ${ }^{(1)}$ & 30.753 & 100,0 & 16.769 & 100,0 & -13.984 & $-45,5$ \\
\hline
\end{tabular}

Fonte: IBGE - PNAD.

Nota: ${ }^{(1)} \mathrm{O}$ valor do salário mínimo vigente em setembro de 2003 foi corrigido (INPC) para R\$ de setembro de 2008. 
Contudo, é necessário tomar cuidado ao interpretar esses dados, uma vez que, durante o governo Lula, foi implantada uma política de elevação substancial do salário mínimo legal (estava estipulado em $\mathrm{R} \$ 240,00$ em 2003, contra R\$ 415,00 em 2008 - um aumento nominal de 72,9\%). Por isso, para observar como a melhoria no poder aquisitivo do salário mínimo interfere nessa análise, é preciso corrigir o valor de corte usado para 2003; ou seja, o valor referente ao salário mínimo em setembro de 2008, corrigido pelo Índice Nacional de Preços ao Consumidor (isto é, descontando a inflação acumulada no período: 29,57\%), correspondia a R \$320,30 em setembro de 2003. Utilizando esse critério, observase uma redução muito pronunciada no número de ocupados com rendimento inferior ao salário mínimo entre 2003 e 2008 (Tabela 5). Em outras palavras, nesses termos, a avaliação do período seria de uma melhoria acentuada no mercado de trabalho brasileiro, ao menos no que se refere à redução do número de ocupados com poder aquisitivo muito baixo (cerca de 14 milhões de pessoas).

Para complementar o diagnóstico da proporção de ocupados que se encontram em situação muito precária ou vulnerável, convém examinar o segmento dos trabalhadores informais que possuem uma remuneração mensal relativamente baixa e não contribuem para um instituto de previdência (seja este público ou privado). Na Tabela 6, procura-se quantificar os ocupados que tinham uma remuneração igual ou superior a 1 s.m., mas inferior a 2 s.m., e que não estavam cobertos por instituto de seguridade social (entre os assalariados, foram considerados aqueles que não tinham registro em carteira de trabalho).

Tabela 6

Ocupados (16 anos ou mais de idade) com rendimento mensal entre 1 e menos de 2 s.m. e sem contribuição para instituto de previdência, de acordo com a posição na ocupação Brasil: 2003 e 2008

\begin{tabular}{lrrrrrr}
\hline \multirow{2}{*}{ Posição na Ocupação Principal } & \multicolumn{2}{c}{2003} & \multicolumn{2}{c}{2008} & \multicolumn{2}{c}{$2008-2003$} \\
\cline { 2 - 7 } & $(1.000)$ & $(\%)$ & $(1.000)$ & $(\%)$ & $(1.000)$ & $(\%)$ \\
\hline Empregado sem carteira assinada & 5.409 & 47,5 & 5.456 & 46,9 & 47 & 0,9 \\
Trabalhador doméstico sem carteira & 1.447 & 12,7 & 1.252 & 10,8 & -195 & $-13,5$ \\
Trabalhador por conta própria & 4.294 & 37,7 & 4.540 & 39,0 & 246 & 5,7 \\
Empregador & 230 & 2,0 & 385 & 3,3 & 155 & 67,2 \\
\hline Total & 11.380 & 100,0 & 11.632 & 100,0 & 252 & 2,2 \\
\hline
\end{tabular}

Fonte: IBGE - PNAD.

Nota: Considerando o valor do salário mínimo vigente em setembro de 2003 e setembro de 2008.

Esse tipo de precariedade atingia uma parcela expressiva dos trabalhadores brasileiros: 11,4 milhões em 2003 e 11,6 milhões em 2008 (o que correspondia a $16 \%$ do total de ocupados com remuneração em 2003 e 14\% em 2008). Nota-se, também, que não houve alteração significativa na distribuição relativa: $47 \%$ desses 
trabalhadores vulneráveis eram empregados sem o registro do vínculo, 39\% eram trabalhadores por conta própria e $11 \%$ eram trabalhadores em serviços domésticos sem carteira assinada. Contudo, é importante considerar que, se o valor do salário mínimo em 2003 fosse corrigido para R\$ de 2008, provavelmente os dados mostrariam uma redução mais expressiva desse tipo de trabalho precário.

\section{Situações mais graves de vulnerabilidade ocupacional no País (2008-2009)}

Depois de examinar as principais variações observadas no período 20032008 (cinco anos de crescimento econômico substantivo) e identificar sinais de melhoria gradual do mercado de trabalho brasileiro, pode-se agora fazer uma estimativa, ainda que grosseira, da dimensão absoluta e relativa da vulnerabilidade ocupacional vista pela ótica da dificuldade de obter um trabalho remunerado, da insuficiência do rendimento mensal e da falta de cobertura da previdência social. A análise está dividida em dois momentos, procurando contrastar a situação registrada antes da crise que se manifestou no último trimestre de 2008 com o quadro apresentado depois de superada a recessão econômica ocorrida no primeiro semestre de 2009. Desse modo, pretende-se verificar a hipótese de que a crise econômica aumentou o número de trabalhadores em situação claramente vulnerável no País. Além de realçar a enorme e persistente dimensão da privação e da precariedade ocupacional, pretende-se também frisar que tais problemas atingem homens e mulheres com intensidades distintas e requerem ações vigorosas e duradouras do poder público em diferentes frentes.

Antes, convém fazer um esclarecimento sobre os conceitos utilizados e a metodologia adotada para sua mensuração. Na literatura internacional, "trabalho precário" (precarious work; precarious employment) é um termo que tem sido usado com diferentes significados, mas predomina o entendimento geral de que está associado com: instabilidade no emprego ou incerteza quanto à continuidade da atividade; falta de proteção em caso de acidente, desemprego ou aposentadoria; péssimas condições de trabalho ou práticas laborais inaceitáveis (incluindo discriminação, jornada de trabalho excessiva e demissão injustificada); rendimento insuficiente que acarreta vulnerabilidade social (Rodgers, 1989). O trabalho precário tem sido mensurado com base em diferentes metodologias, dependendo das características do mercado de trabalho (tais como o grau de flexibilidade e o tipo de regulação social) e do entendimento a respeito de qual é o padrão de emprego aceitável ou desejável (Barbier; Brygoo; Viguier, 2002). Por exemplo, os estudos que enfocam o crescimento da insegurança e da precariedade em países desenvolvidos apresentam uma abordagem distinta daqueles que analisam a dimensão do problema em países latino-americanos, onde prevalece uma alta taxa de informalidade (Kalleberg, 2009). Do mesmo modo, diferentes critérios têm sido usados para estimar a incidência de trabalhadores com "baixos salários", variando 
conforme o grau de desenvolvimento de cada economia nacional (Grimshaw, 2011). Evidentemente, diferenças metodológicas podem produzir diagnósticos divergentes e dar embasamento para distintas explicações sobre a expansão do trabalho precário nas últimas décadas, colocando em discussão as políticas mais adequadas para enfrentar o problema (Evans; Gibb, 2009).

Por sua vez, na literatura internacional, é comum encontrar estudos que utilizam a expressão "trabalhador vulnerável" (vulnerable worker) como um sinônimo de trabalhador em situação precária. Entretanto, o conceito também tem sido definido de maneiras variadas e empregado com diferentes finalidades. Uma abordagem frequente é aquela que define os grupos de trabalhadores cuja condição ocupacional coloca em risco seu bem-estar, tais como os trabalhadores por conta própria que não estão cobertos pela legislação trabalhista, os empregados que se sujeitam a abusos do empregador por medo de perder o emprego, aqueles que não têm acesso ao benefício do seguro-desemprego ou a planos de saúde e aposentadoria e os que não encontram trabalho regular e passam muito tempo recebendo baixos rendimentos (Saunders, 2003). Em outros documentos, o termo "vulnerabilidade" tem um escopo mais estreito, circunscrito a situações em que há alto risco de serem negados os direitos do trabalhador, e este não tem capacidade ou meios de fazer valer seus direitos, como no caso de imigrantes (United Kingdom-DTI, 2006). E há abordagens alternativas: por exemplo, em artigo recente, os trabalhadores vulneráveis são identificados pela combinação entre baixa remuneração e falta de representação sindical associadas com a exclusão do sistema público de proteção ao trabalho (Pollert; Charlwood, 2009). No Brasil, a análise da vulnerabilidade no mercado de trabalho tem enfatizado as características pessoais que conferem desvantagens competitivas e tem destacado as formas de inserção precária que correspondem a uma condição intermediária entre o desemprego e o trabalho decente (Dieese; Unicamp, 2007). Por fim, convém ressaltar que os diagnósticos mais pertinentes costumam elencar um gradiente de vulnerabilidades no mercado de trabalho, podendo variar bastante a metodologia adotada e os critérios para definir a "vulnerabilidade ocupacional".

Nesta seção, são priorizadas as principais formas de insegurança e inserção precária encontradas no mercado de trabalho brasileiro, mas é preciso esclarecer que alguns aspectos relevantes não foram contemplados, tais como a jornada semanal de trabalho muito extensa. O diagnóstico apresentado a seguir baseia-se em informações oferecidas pela PNAD (IBGE). Para facilitar a análise, foram definidos quatro grupos de trabalhadores em situação vulnerável que decorrem dos principais problemas recorrentes no mercado de trabalho brasileiro referidos anteriormente (desemprego crônico, subemprego, informalidade, baixos salários e desproteção social). O primeiro grupo refere-se aos desempregados em situação mais grave, isto é, aos que declararam não estar trabalhando e ter procurado 
emprego durante um período superior a seis meses ${ }^{7}$. O segundo diz respeito àqueles privados de um trabalho remunerado, incluindo os ocupados em atividade não mercantil (produção para consumo próprio ou construção para uso próprio) e os trabalhadores sem remuneração. O terceiro grupo corresponde aos que exercem um trabalho informal com rendimento mensal inferior ao mínimo legal, incluindo empregados sem registro em carteira, trabalhadores por conta própria, trabalhadores domésticos sem carteira e mesmo empregadores. E o quarto corresponde aos trabalhadores que não contribuem para instituto de previdência e recebem uma remuneração relativamente baixa, mas não inferior ao mínimo legal (faixa de rendimento mensal arbitrariamente definida entre 1 s.m. e menos de 2 s.m.).

Tabela 7

Estimativa do número de trabalhadores em situação ocupacional vulnerável, por sexo - Brasil: 2008

\begin{tabular}{|c|c|c|c|c|c|c|}
\hline \multirow{2}{*}{ Situação ocupacional } & \multicolumn{2}{|c|}{ Masculino } & \multicolumn{2}{|c|}{ Feminino } & \multicolumn{2}{|c|}{ Total } \\
\hline & $(1.000)$ & $(\%)$ & $(1.000)$ & $(\%)$ & $(1.000$ & $(\%)$ \\
\hline PEA (16 anos ou mais) & 54.035 & 100,0 & 42.714 & 100,0 & 96.749 & 100,0 \\
\hline População ocupada & 50.932 & 94,3 & 38.099 & 89,2 & 89.031 & 92,0 \\
\hline População desocupada & 3.103 & 5,7 & 4.614 & 10,8 & 7.718 & 8,0 \\
\hline 1. Desempregado crônico (mais de 6 meses) & 835 & 1,5 & 1.241 & 2,9 & 2.076 & 2,1 \\
\hline \multicolumn{7}{|l|}{ 2. Trabalhador privado de atividade remunerada } \\
\hline a. Ocupado em atividade não mercantil & 1.435 & 2,7 & 2.338 & 5,5 & 3.773 & 3,9 \\
\hline b. Ocupado em trabalho não remunerado & 1.195 & 2,2 & 2.269 & 5,3 & 3.464 & 3,6 \\
\hline Subtotal $1(a+b)$ & 2.630 & 4,9 & 4.607 & 10,8 & 7.237 & 7,5 \\
\hline \multicolumn{7}{|c|}{ 3. Trabalhador informal com rendimento menor que 1 s.m. } \\
\hline c. Empregado sem carteira assinada & 3.772 & 7,0 & 1.952 & 4,6 & 5.724 & 5,9 \\
\hline d. Trabalhador doméstico sem carteira & 100 & 0,2 & 3.052 & 7,1 & 3.152 & 3,3 \\
\hline e. Trabalhador por conta própria & 4.072 & 7,5 & 3.269 & 7,7 & 7.341 & 7,6 \\
\hline f. Empregador & 145 & 0,3 & 60 & 0,1 & 205 & 0,2 \\
\hline Subtotal $2(c+d+e+f)$ & 8.089 & 15,0 & 8.332 & 19,5 & 16.421 & 17,0 \\
\hline \multicolumn{7}{|c|}{ 4. Trabalhador informal sem contribuição à previdência e com rendimento entre 1 e 2 s.m. } \\
\hline g. Empregado sem carteira assinada & 3.771 & 7,0 & 1.685 & 3,9 & 5.456 & 5,6 \\
\hline h. Trabalhador doméstico sem carteira & 106 & 0,2 & 1.146 & 2,7 & 1.252 & 1,3 \\
\hline i. Trabalhador por conta própria & 3.277 & 6,1 & 1.263 & 3,0 & 4.540 & 4,7 \\
\hline j. Empregador & 281 & 0,5 & 104 & 0,2 & 385 & 0,4 \\
\hline Subtotal $3(\mathrm{~g}+\mathrm{h}+\mathrm{i}+\mathrm{j})$ & 7.434 & 13,8 & 4.199 & 9,8 & 11.632 & 12,0 \\
\hline Total $(1+2+3+4)$ & 18.988 & 35,2 & 18.379 & 43,0 & 37.366 & 38,6 \\
\hline Trabalhadores em situação precária $(2+3+4)$ & 18.153 & $33,7^{1}$ & 17.138 & $40,1^{1}$ & 35.290 & $36,5^{1}$ \\
\hline
\end{tabular}

Fonte: IBGE - PNAD.

Nota: ${ }^{(1)}$ Porcentagem de trabalhadores em situação muito precária em relação ao total de pessoas ocupadas.

(7) Outros estudos não consideram os desempregados como trabalhadores vulneráveis. De fato, nesse caso, o grau de vulnerabilidade depende de vários fatores, em especial do tempo médio de procura por emprego, da cobertura do seguro-desemprego e dos programas de auxílio aos desempregados. Também depende, em geral, do perfil do indivíduo (idade, sexo, raça, grau de instrução, renda familiar e tempo de residência no município). 
Na Tabela 7 , nota-se que mais de 9 milhões de pessoas $(9,6 \%$ da PEA) estavam desempregadas havia mais de seis meses ${ }^{8}$ ou privadas de uma ocupação remunerada em setembro de 2008. Por sua vez, somando o terceiro e o quarto grupos, havia mais de 28 milhões de trabalhadores (29\% da PEA) em atividades informais com rendimento insatisfatório e falta de proteção social. Definindo a vulnerabilidade ocupacional de acordo com esses critérios, pode-se dizer que, no conjunto, 37,4 milhões de trabalhadores brasileiros (38,6\% da PEA) estavam expostos a algum tipo grave de insegurança ou precariedade ${ }^{9}$. Sem computar os desempregados, havia 35,3 milhões de ocupados (36,5\% da população ocupada) em situações que podem ser associadas com o termo "trabalho precário".

Outra constatação importante a destacar na Tabela 7 é a maior incidência de situações vulneráveis entre as mulheres em comparação com os homens. Em termos absolutos, o número de mulheres economicamente ativas era bem menor que o de homens. Contudo, o número de mulheres que se encontravam desempregadas de forma crônica ou privadas de um trabalho remunerado era bem maior (5,8 milhões contra 3,5 milhões). No que se refere aos postos de trabalho informais com rendimentos mensais menores que o salário mínimo, havia certo equilíbrio entre mulheres e homens (8,3 milhões e 8,1 milhões). Somando os quatro grupos, havia 18,4 milhões de mulheres em condição ocupacional vulnerável em 2008, sendo que 17,1 milhões estavam em situação ocupacional muito precária (entre os homens, 19 milhões e 18,2 milhões, respectivamente). Por sua vez, em termos relativos, a condição ocupacional mais desfavorável das mulheres fica ainda mais evidente: somados, os quatro grupos vulneráveis englobavam $43 \%$ da PEA feminina e 35\% da PEA masculina. Finalmente, é válido ressaltar que a precariedade ocupacional (somando aqueles três grupos) também era proporcionalmente maior entre as mulheres: $40 \%$ da população feminina ocupada e um terço dos homens ocupados estavam em situações aqui classificadas como "trabalho precário".

Certamente, esses trabalhadores (homens e mulheres) privados de um trabalho remunerado ou expostos a situações informais muito precárias em 2008 estavam todos excluídos de um trabalho decente, qualquer que seja o critério de

(8) A PNAD não possui esse tipo de registro. Para uma estimativa aproximada, considerou-se a informação fornecida pela Pesquisa Mensal de Emprego, também do IBGE. De acordo com a PME, em setembro de 2008, os desempregados procurando trabalho havia mais de 6 meses representavam 26,9\% do total de desempregados no conjunto das seis regiões metropolitanas pesquisadas. Em setembro de 2009, essa proporção era de $27,9 \%$.

(9) Em 2003, em termos relativos, o quadro era o seguinte: 12,8\% da PEA estavam desempregados havia mais de 6 meses ou trabalhavam sem remuneração monetária, 14,9\% tinham remuneração inferior ao salário mínimo nominal e $13,1 \%$ não estavam cobertos pela previdência social e ganhavam menos de 2 s.m. mensais. Ou seja, esses quatro grupos de trabalhadores vulneráveis somados atingiam 44,9\% da PEA. Certamente, se o valor do salário mínimo em 2003 fosse corrigido para $\mathrm{R} \$$ de setembro/2008, essa porcentagem seria ainda maior e indicaria uma redução expressiva da vulnerabilidade ocupacional durante o período. 
análise. Contudo, convém frisar que a metodologia utilizada neste estudo não é apropriada para estimar o déficit de trabalho decente no Brasil. Por exemplo, não foram computados os trabalhadores informais com rendimento mensal igual ou superior a 2 salários mínimos, mas que apresentam lacunas em relação a outras dimensões estabelecidas pela OIT. De qualquer modo, as situações mais vulneráveis aqui examinadas constituem o núcleo duro do problema em discussão.

A pergunta que se coloca, agora, é a seguinte: a crise econômica que se manifestou a partir de outubro de 2008 provocou um aumento significativo da vulnerabilidade no mercado de trabalho nacional? Aumentou o número de trabalhadores em situação claramente precária?

O último trimestre de 2008, no Brasil, foi marcado por forte desaceleração da atividade econômica seguida por um período recessivo nos dois primeiros trimestres de 2009. Sem dúvida, a crise afetou o mercado de trabalho nacional, refletindo-se no aumento da taxa de desemprego e na redução do emprego industrial. Porém, a economia brasileira apresentava fundamentos firmes para resistir aos impactos da crise e se recuperou rapidamente, em boa medida por causa da resposta do governo federal em várias frentes. Em especial, devem ser mencionadas as políticas destinadas a preservar a oferta de crédito, a favorecer setores-chave, a estimular o investimento e a proteger a população de baixa renda, isto é, políticas que sustentaram a demanda agregada e, dessa forma, contribuíram para preservar empregos e evitar uma forte deterioração do mercado de trabalho (OIT, 2011b).

A Tabela 8 permite constatar que, entre setembro de 2008 e setembro de 2009, não houve crescimento do número de trabalhadores vulneráveis no País: somando os quatro grupos considerados, cerca de 37,3 milhões de trabalhadores brasileiros $(37,8 \%$ da PEA) estavam numa situação ocupacional muito insatisfatória ou não tinham uma inserção remunerada em setembro de 2009. Passado o período recessivo, houve uma recuperação do mercado de trabalho no terceiro trimestre do ano, não sendo possível captar pela PNAD os efeitos mais graves da crise econômica sobre os trabalhadores.

Contudo, observando os grupos separadamente, pode-se dizer que a crise teve impactos distintos sobre os trabalhadores considerados mais vulneráveis. Por um lado, é importante destacar que houve um aumento no número estimado de desempregados crônicos (em mais de 400 mil pessoas), sendo que o total dos que se declararam desempregados se elevou de 7,7 milhões para 9 milhões de pessoas entre 2008 e 2009. Por outro lado, a PNAD-2009 indica que diminuiu a proporção estimada de pessoas que estavam privadas de trabalho remunerado (de 7,5\% para $6,9 \%$ da PEA), ao passo que se manteve a porcentagem de trabalhadores informais com um rendimento mensal inferior ao salário mínimo (17\% da PEA) e se reduziu 
ligeiramente a porção de trabalhadores informais sem contribuição previdenciária e com rendimento mensal entre 1 s.m. e menos de 2 s.m. (11,5\% da PEA). Assim, estima-se que o número de trabalhadores em situações qualificadas aqui como "trabalho precário" se reduziu um pouco entre setembro de 2008 e setembro de 2009, mas englobava ainda 34,8 milhões de ocupados (35,3\% da população economicamente ocupada).

Tabela 8

Estimativa do número de trabalhadores em situação ocupacional vulnerável, por sexo Brasil: 2009

\begin{tabular}{|c|c|c|c|c|c|c|}
\hline \multirow{2}{*}{ Situação ocupacional } & \multicolumn{2}{|c|}{ Masculino } & \multicolumn{2}{|c|}{ Feminino } & \multicolumn{2}{|c|}{ Total } \\
\hline & $(1.000)$ & $(\%)$ & $(1.000)$ & $(\%)$ & $(1.000)$ & $(\%)$ \\
\hline PEA (16 anos ou mais) & 54.631 & 100,0 & 43.718 & 100,0 & 98.349 & 100,0 \\
\hline População ocupada & 50.995 & 93,3 & 38.375 & 87,8 & 89.370 & 90,9 \\
\hline População desocupada & 3.636 & 6,7 & 5.343 & 12,2 & 8.979 & 9,1 \\
\hline 1. Desempregado crônico (mais de 6 & 1.014 & 1,9 & 1.491 & 3,4 & 2.505 & 2,5 \\
\hline \multicolumn{7}{|c|}{ 2. Trabalhador privado de atividade remunerada } \\
\hline a. Ocupado em atividade não mercantil & 1.393 & 2,5 & 2.116 & 4,8 & 3.509 & 3,6 \\
\hline b. Ocupado em trabalho não remunerado & 1.134 & 2,1 & 2.150 & 4,9 & 3.284 & 3,3 \\
\hline Subtotal $1(a+b)$ & 2.527 & 4,6 & 4.266 & 9,7 & 6.793 & 6,9 \\
\hline \multicolumn{7}{|c|}{ 3. Trabalhador informal com rendimento menor que 1 s.m. } \\
\hline c. Empregado sem carteira assinada & 3.815 & 7,0 & 1.846 & 4,2 & 5.661 & 5,8 \\
\hline d. Trabalhador doméstico sem carteira & 118 & 0,2 & 3.293 & 7,5 & 3.411 & 3,5 \\
\hline e. Trabalhador por conta própria & 4.130 & 7,6 & 3.364 & 7,7 & 7.494 & 7,6 \\
\hline f. Empregador & 95 & 0,2 & 36 & 0,1 & 132 & 0,1 \\
\hline Subtotal $2(c+d+e+f)$ & 8.158 & 14,9 & 8.539 & 19,5 & 16.698 & 17,0 \\
\hline \multicolumn{7}{|c|}{ 4. Trabalhador informal sem contribuição à previdência e com rendimento entre 1 e 2 s.m. } \\
\hline g. Empregado sem carteira assinada & 3.546 & 6,5 & 1.508 & 3,4 & 5.053 & 5,1 \\
\hline h. Trabalhador doméstico sem carteira & 114 & 0,2 & 1.185 & 2,7 & 1.299 & 1,3 \\
\hline i. Trabalhador por conta própria & 3.304 & 6,0 & 1.276 & 2,9 & 4.580 & 4,7 \\
\hline j. Empregador & 268 & 0,5 & 73 & 0,2 & 341 & 0,3 \\
\hline Subtotal $3(g+h+i+j)$ & 7.232 & 13,2 & 4.042 & 9,2 & 11.273 & 11,5 \\
\hline Total $(1+2+3+4)$ & 18.931 & 34,7 & 18.338 & 41,9 & 37.269 & 37,8 \\
\hline Trabalhadores em situação precária & 17.917 & $32,8^{1}$ & 16.847 & $38,5^{1}$ & 34.764 & $35,3^{1}$ \\
\hline
\end{tabular}

Nota: (1) Porcentagem de trabalhadores em situação muito precária em relação ao total de pessoas ocupadas.

Fonte: IBGE - PNAD.

Voltando à perspectiva da desigualdade por gênero, manteve-se a condição mais vulnerável das mulheres em comparação com a dos homens. Em termos absolutos, o número de mulheres cronicamente desempregadas ou privadas de um 
trabalho remunerado continuava bem maior (6,1 milhões contra 3,6 milhões), correspondendo a $13,1 \%$ das mulheres e $6,5 \%$ dos homens. No que se diz respeito aos trabalhadores informais com rendimentos mensais menores que o salário mínimo, manteve-se certa equivalência entre mulheres e homens (8,5 milhões e 8,2 milhões), sendo importante notar que proporcionalmente essa precariedade afetava mais as mulheres que os homens (19,5\% contra $15 \%)$. Considerando em conjunto os quatro grupos, o total de mulheres em situação vulnerável manteve-se em 18,3 milhões, ao passo que entre os homens o total se manteve próximo de 19 milhões. Por sua vez, a estimativa da porcentagem de ocupados em situação precária reduziu-se um pouco, embora se mantendo no mesmo patamar: $33 \%$ entre os homens e $39 \%$ entre as mulheres em 2009.

Para realizar um diagnóstico mais detalhado sobre o trabalho precário no Brasil, seria conveniente considerar as diferenças regionais quanto à estrutura ocupacional $^{10}$ e mapear as especificidades do mercado de trabalho em cada mesorregião do País. Certamente, os problemas apontados têm relação com o baixo dinamismo na geração de empregos e com as estratégias de sobrevivência das famílias. Contudo, uma análise dessa envergadura não poderia ser tentada nos limites deste artigo. Em complemento, também seria aconselhável examinar a distribuição das precariedades por faixas etárias. Em geral, a informalidade, a baixa remuneração e a falta de contribuição à previdência social não são entendidas como problemas graves entre trabalhadores com idade inferior a $20 \operatorname{anos}^{11}$, o mesmo acontecendo entre trabalhadores com idade superior a 60 anos (se estão aposentados, mas continuam trabalhando).

É importante frisar que a presente mensuração dos problemas mais graves enfrentados pelos trabalhadores procura explicitar as situações definidas como inaceitáveis diante da noção de cidadania inscrita na Constituição Federal - e que são, inclusive, incompatíveis com o atual estágio de desenvolvimento econômico do País. Como mencionado, as formas de vulnerabilidade ocupacional aqui quantificadas são acompanhadas, em maior ou menor grau, por outras precariedades frequentes no mercado de trabalho nacional, tais como: elevada rotatividade no emprego, jornada semanal muito extensa, local de trabalho inadequado, baixa capacidade de organização sindical e alta discrepância salarial por sexo e raça.

Por fim, convém esclarecer que, respeitando a Constituição Federal, o ideal seria que adolescentes com idade inferior a 16 anos não fizessem parte da

(10) Por exemplo, a vulnerabilidade no mercado de trabalho é maior no Nordeste do que no Sudeste, mas a crise recente afetou com intensidade maior as áreas mais industrializadas (Araújo; Lima, 2010).

(11) Os problemas enfrentados pela juventude no mercado de trabalho não devem ser minimizados, uma vez que contribuem para agravar outros problemas sociais e criam dificuldades adicionais para a renovação do movimento sindical (Druck; Oliveira; Jesus, 2010). 
população economicamente ativa (PEA) - ou, pelo menos, que não começassem a trabalhar com menos de 14 anos. Nesse sentido, é importante sublinhar que, apesar dos avanços obtidos ao longo da década, o trabalho infantil permanecia constituindo um problema sério no Brasil. De acordo com a Comissão Nacional de Erradicação do Trabalho Infantil, ainda havia 785 mil ocupados na faixa etária entre 10 e 13 anos ao final da década. Além disso, cerca de 123 mil crianças (na faixa etária entre 5 e 9 anos) estavam exercendo algum tipo de atividade econômica. Portanto, pode-se dizer que o trabalho infantil abrangia, em 2009, mais de 908 mil crianças e pré-adolescentes (3,1\% da população entre 5 e 13 anos), sendo que a imensa maioria pertencia a famílias rurais pobres, trabalhava na agricultura e não recebia remuneração monetária. Acrescente-se que, entre os adolescentes com idade entre 14 e 15 anos, 1.153 mil $(16,1 \%)$ declararam trabalhar em 2009. Contudo, estes não estavam em treinamento ou atividade formadora, uma vez que apenas 98 mil jovens entre 14 e 18 anos estavam registrados como aprendizes naquela época. Dessa forma, o problema do trabalho infantil englobava em torno de 2 milhões de crianças e jovens entre 5 e 15 anos de idade (BRASIL. Conaeti, 2011). E vale ressaltar que as famílias que recorrem ao trabalho infantil, em geral, são aquelas nas quais todos os membros adultos apresentam uma situação ocupacional muito precária ou vulnerável ${ }^{12}$.

\section{Considerações finais}

Não há dúvida quanto à existência de distintos graus de vulnerabilidade e precariedade ocupacional no Brasil. Neste artigo, foram priorizadas situações associadas à falta crônica de trabalho (o desemprego de longa duração) ou a uma condição muito precária (o trabalho sem remuneração, o emprego sem registro, a remuneração acentuadamente baixa, a falta de contribuição para a previdência social), que se manifestam em diferentes formas de inserção informal no mercado de trabalho. A análise procurou destacar que tais problemas recorrentes atingem parcelas expressivas dos trabalhadores.

A argumentação desenvolvida aqui pretendeu ressaltar que os desafios para reduzir radicalmente os problemas enfrentados por segmentos expressivos da população no mercado de trabalho brasileiro são de diferentes ordens e requerem ações e programas com distintos desenhos e alcances. Pode-se supor que, entre as quase 35 milhões de pessoas em situação ocupacional muito precária em setembro de 2009, havia chances muito desiguais de conseguir escapar da informalidade ou de obter um trabalho decente. De modo análogo, entre os 9 milhões de

(12) É importante mencionar que, num conjunto de 9,28 milhões famílias rurais, havia 2,46 milhões $(26,5 \%)$ cuja renda mensal total não ultrapassava um salário mínimo, ao passo que, entre as famílias residentes em domicílios urbanos, 6,32 milhões (11,9\%) tinham renda mensal menor ou igual a um salário mínimo (IBGE, 2009). 
desempregados, as chances de obter um emprego regular dependiam muito do perfil do trabalhador (em geral, aqueles que estavam procurando trabalho havia mais de seis meses se encontravam numa situação mais vulnerável).

É oportuno ressaltar que o desempenho favorável do mercado de trabalho brasileiro durante os cinco anos que antecederam a crise econômica - período em que houve uma redução significativa dos percentuais de ocupados expostos àqueles tipos de vulnerabilidade - só foi possível graças ao ritmo de crescimento da economia e à política de valorização do salário mínimo. Além disso, contou com a atuação das instituições públicas (Ministério do Trabalho e Emprego, Ministério Público do Trabalho e Justiça do Trabalho), com avanços no terreno das negociações coletivas e com o apoio das políticas no campo da proteção social (Baltar et al., 2010). Não obstante, em setembro de 2008, ao final daquele período de razoável expansão econômica, o número de pessoas desempregadas e a quantidade de trabalhadores precários permaneciam muito elevados no Brasil. Como desdobramento da análise, pode-se supor que seria necessário manter tais condições favoráveis durante um período de tempo bem mais extenso - talvez durante vinte anos ou mais - para que tais vulnerabilidades ocupacionais possam ser amplamente superadas (note-se que muitos trabalhadores brasileiros não têm condições de uma inserção adequada num mercado de trabalho competitivo e continuariam precisando do apoio de programas de assistência social).

Ainda que em 2009 a crise não tenha alcançado, no mercado de trabalho nacional, a gravidade que se temia (uma vez que a taxa mensal de desemprego voltou rapidamente a mostrar uma trajetória declinante, o rendimento médio seguiu uma trajetória de aumento gradual e o processo de formalização do emprego permaneceu indicando uma tendência de redução da informalidade e da desproteção social), é preciso reforçar o compromisso de somar esforços para proteger os trabalhadores em situação mais precária, combater as distintas modalidades de vulnerabilidade ocupacional e reduzir desigualdades ${ }^{13}$. E é preciso retomar a discussão sobre o enfrentamento das graves questões estruturais no âmbito do mercado de trabalho que continuam dificultando o desenvolvimento nacional.

Um dos maiores desafios é a redução do imenso excedente estrutural de mão de obra. Somando os 9 milhões de desempregados com os 6,8 milhões de trabalhadores em atividades não remuneradas e os 16,7 milhões de trabalhadores informais com remuneração menor do que o salário mínimo legal, o contingente que se pode chamar de "exército de reserva" atingiu quase 32,5 milhões de

(13) Por exemplo, segundo o Ministério do Trabalho e Emprego, foram beneficiados aproximadamente 7,7 milhões de trabalhadores com o seguro-desemprego em 2009. Mas só empregados com vínculo registrado em carteira têm direito ao benefício, deixando sem assistência financeira os trabalhadores informais que perdem o emprego. 
trabalhadores - cerca de um terço (33\%) da PEA brasileira em 2009. Mas esse número era ainda maior, uma vez que podem ser adicionadas as pessoas tidas como economicamente inativas apenas por não terem procurado emprego na semana da pesquisa ("desemprego oculto por desalento"). Sem dúvida, a oferta excessiva de trabalhadores (tanto no campo como nas cidades) ajuda a explicar os baixos salários e a enorme informalidade que afligem a maioria dos trabalhadores brasileiros. Não obstante, deve-se ter em mente que boa parte desse contingente não estava apta a ser recrutada para ocupar uma vaga de emprego no setor formal da economia, configurando segmentos permanentemente marginalizados.

Até a deflagração da crise internacional, o debate em torno das políticas públicas mais adequadas para superar os problemas aqui apontados tinha ficado restrito aos círculos acadêmicos e mobilizado muito pouco os setores organizados da sociedade brasileira. Provavelmente em razão do cenário econômico claramente favorável entre 2004-2008 e das tendências encorajadoras do mercado de trabalho, parece ter predominado a suposição de que as principais vulnerabilidades ocupacionais poderiam continuar a se reduzir paulatinamente, bastando manter as mesmas políticas. O papel do governo federal seria, grosso modo, garantir as condições para a sustentação do crescimento, de um lado, e manter a política de valorização do salário mínimo e os programas de transferência de renda para reduzir a pobreza e a desigualdade social, de outro.

Os dados apresentados sugerem que o desafio de promover o trabalho decente não pode ser subestimado. A recuperação da economia e a estabilidade macroeconômica devem ser entendidas como condições necessárias, mas não suficientes, para garantir uma geração adequada de empregos, uma elevação significativa do poder de compra dos salários e uma redução expressiva da miséria e das desigualdades sociais (Pochmann, 2011) ${ }^{14}$. E as iniciativas no campo da regulação do mercado de trabalho, do fortalecimento da ação sindical, da redistribuição de renda e da universalização da proteção social precisariam ser não apenas preservadas, mas amplificadas e incrementadas para que possam produzir os resultados almejados. Em outras palavras, no início do governo Dilma, apesar das expectativas otimistas de crescimento sustentado da economia brasileira em razão das descobertas de reservas de petróleo e do compromisso com a erradicação da miséria, não havia motivos para que fossem subestimadas as dificuldades de superação da vulnerabilidade ocupacional no País.

Existem diferentes opiniões a respeito das melhores estratégias para a promoção do trabalho decente e a superação da precariedade ocupacional no Brasil. Embora a maioria dos estudos publicados pela OIT sugira que a generalização do

(14) A análise do processo de mobilidade social verificado entre 2003-2009, no Brasil, revela o potencial e os limites do atual modelo de inclusão social por meio do trabalho (Quadros, 2011). 
trabalho decente corresponde, necessariamente, a uma progressiva eliminação da informalidade, há autores que afirmam ser possível "incorporar a informalidade na modernidade" e compatibilizar a flexibilidade da economia informal com a segurança propiciada pelos direitos trabalhistas (Tokman, 2009). Sem pretender entrar nesse debate, este artigo procurou enaltecer a Agenda do Trabalho Decente, que indica claramente ser preciso priorizar ações em defesa de empregos regulares, com registro em carteira e imunes a condições desumanas, assim como combater toda forma de discriminação ${ }^{15}$. Apenas dessa maneira se pode estabelecer um ambiente mais favorável aos trabalhadores e fazer respeitar os seus direitos sociais no mundo contemporâneo (OIT, 2008).

Deve-se ressaltar que, desde 2008, o contexto internacional mudou completamente e novas formas de intervenção estatal passaram a ser demandadas em vários países, inclusive no mercado de trabalho. Em meio à crise econômica, a OIT voltou a argumentar que era preciso redirecionar o estilo do desenvolvimento mundial para evitar o aumento explosivo do desemprego e da pobreza tanto nas regiões mais avançadas como nas mais atrasadas. Para combater os efeitos sociais perversos da crise, lançou o "Pacto Mundial para o Emprego", cujas prioridades convergem totalmente com a Agenda do Trabalho Decente: a) investir no futuro, criando empregos e aumentando as transferências de renda; b) prevenir um declínio do poder de compra dos salários e promover uma recuperação liderada pelo consumo interno; c) manter e ampliar a proteção social (Hoffer, 2011).

Na América Latina, em 2010, houve avanços em alguns indicadores que comprovam a recuperação dos mercados de trabalho na região, fazendo crer que o período mais crítico da crise havia sido ultrapassado. Porém, o desafio de combater a informalidade, eliminar o trabalho precário e promover o trabalho decente continuava imenso. Por isso, a OIT afirmou que a adoção de ações efetivas nessa direção não deveria ser adiada (Somavia, 2010).

No caso do Brasil, um dos motivos de ser relativamente lento o avanço em muitos pontos prioritários na agenda pública para o trabalho diz respeito ao fato de haver uma "cultura da informalidade" arraigada em todas as regiões do País, a qual está associada com certa tolerância em relação às várias precariedades aqui apontadas. Daí a necessidade de difundir e enraizar uma "cultura do trabalho decente" e uma aversão profunda às situações de clara vulnerabilidade ocupacional.

Recentemente, algumas iniciativas foram tomadas nesse sentido. Em 2010, o governo federal aprovou um Plano Nacional de Emprego e Trabalho Decente

(15) Além da ampla variedade de políticas públicas que podem ser adotadas para combater o trabalho precário e promover o trabalho decente, é preciso considerar ainda uma série de estratégias sindicais específicas, que poderiam atuar na mesma direção (Evans; Gibb, 2009). 
(Brasil. MTE, 2010) e lançou a I Conferência Nacional de Emprego e Trabalho Decente, cujo objetivo maior é fomentar um amplo debate envolvendo a temática das políticas públicas de trabalho, emprego e proteção social (com a participação de representantes de empregadores e de trabalhadores, bem como de outras organizações sociais e autoridades governamentais), o que permitirá desenhar e implantar uma Política Nacional de Emprego e Trabalho Decente ${ }^{16}$. Ao levar em conta a diversidade de demandas presentes na sociedade brasileira, essas iniciativas podem permitir que se aglutinem forças políticas em torno de um projeto de desenvolvimento nacional capaz de incluir produtivamente o conjunto da força de trabalho, melhorar de forma sustentável a eficiência do mercado de trabalho, diminuir de maneira expressiva a vulnerabilidade ocupacional e garantir de modo consistente o exercício da cidadania. De qualquer forma, como mudanças culturais são lentas e há fortes resistências a um projeto dessa envergadura, será preciso aguardar vários anos para que as sementes possam vingar e para que tais iniciativas possam dar frutos.

\section{Referências}

ABRAMO, Laís; SANCHES, Solange; COSTANZI, Rogério. Análise preliminar dos déficits de trabalho decente no Brasil no período 1992-2006. In: ENCONTRO NACIONAL DE ESTUDOS POPULACIONAIS, 16, ABEP, Caxambu-MG, 29 set. a 3 out. 2008. Coletânea...

; BOLZÓN, Andrea; RAMOS, Christian. Agenda do trabalho decente. In: BUAINAIN, A. M.; DEDECCA, C. S. (Org.). Emprego e trabalho na agricultura brasileira. Brasília: IICA, 2008.

ARAÚJO, Tarcísio P. de; LIMA, Roberto A. de. Aspectos estruturais do mercado de trabalho em contexto recente da economia brasileira: contraponto Nordeste-Sudeste. In: MORETTO, A. et al. (Org.). Economia, desenvolvimento regional e mercado de trabalho do Brasil. Fortaleza: IDT; BNB; Cesit, 2010.

BALTAR, Paulo et al. Trabalho no governo Lula: uma reflexão sobre a recente experiência brasileira. GLU, 2010. (Global Labour University Working Papers, n. 9).

BARBIER, Jean-Claude; BRYGOO, Angélina; VIGUIER, Frédéric. Defining and assessing precarious employment in Europe: a review of main studies and surveys. A tentative approach to precarious employment in France. Paris: Centre d'Études de l'Emploi, 2002. (ESOPE Project).

BERG, J.; RIBEIRO, J. Evolução recente do trabalho decente no Brasil: avanços e desafios. Mercado de Trabalho: conjuntura e análise. IPEA, ano 15, n. 44, p. 19-28, ago. 2010.

(16) Em acréscimo, em 2011, foi aprovada a Agenda Nacional de Trabalho Decente para a Juventude (Brasil. MTE, 2011), indicando a preocupação com a situação dos trabalhadores que estão num estágio inicial de sua trajetória profissional. 
BRASIL. CONAETI. Plano nacional de prevenção e erradicação do trabalho infantil e proteção do adolescente trabalhador. Comissão Nacional de Erradicação do Trabalho Infantil. 2. ed. Brasília: Ministério do Trabalho e Emprego, 2011.

BRASIL. MTE. Agenda nacional de trabalho decente. Brasília: Ministério do Trabalho e Emprego, 2006.

Plano nacional de emprego e trabalho decente. Brasília: Ministério do Trabalho e Emprego, 2010.

- Agenda nacional de trabalho decente para a juventude. Brasília: Ministério do Trabalho e Emprego, Secretaria Executiva, jun. 2011.

CACCIAMALI, Maria Cristina. Crescimento econômico, expansão do mercado de trabalho formal e distribuição de renda do trabalho: a primeira década do século XXI. Trabalho em Questão, SEP, Salvador, n. 86, p. 43-58, 2010.

CEPAL. Estudio económico de América Latina y el Caribe, 2008-2009. Santiago de Chile: Naciones Unidas, 2009.

CEPAL. La hora de la igualdad: brechas por cerrar, caminos por abrir. $33^{\circ}$ periodo de sesiones de la CEPAL. Santiago de Chile: Naciones Unidas, 2010.

CEPAL/PNUD/OIT. Emprego, desenvolvimento humano e trabalho decente: a experiência brasileira recente. Brasília, set. 2008.

DIEESE; UNICAMP. Aspectos conceituais e metodológicos da vulnerabilidade social. Brasília: Ministério do Trabalho e Emprego, 2007. (Projeto de Qualificação Social para Atuação de Sujeitos na Negociação Coletiva e na Gestão de Políticas Públicas, Subprojeto IV, Paper 9).

DRUCK, Graça; OLIVEIRA, Luiz Paulo J. de; JESUS, Selma C. S. Precarização social do trabalho no Brasil: o caso da vulnerabilidade dos jovens e dos sindicatos. Trabalho em Questão, SEP, Salvador, n. 86, p. 103-130, 2010.

EVANS, John; GIBB, Euan. Moving from precarious employment to decent work. Geneva: Global Union Research Network, ILO, 2009. (GURN Discussion Paper, n. 13).

GRIMSHAW, Damian. What do we know about low-wage work and low-wage workers? Analysing the definitions, patterns, causes and consequences in international perspective. Conditions of Work and Employment Series, ILO, Geneva, n. 28, 2011.

HOFFER, Frank. The great recession: a turn point for labour? International Journal of Labour Research, v. 2, issue 1, p. 99-117, 2010.

IBGE. Pesquisa Nacional por Amostra de Domicílios. Rio de Janeiro, 2009. v. 30.

ILO. Globalization and decent work in the Americas. XV American Regional Meeting. Report of the Director-General. Lima: International Labour Organization, Dec. 2002.

KALLEBERG, Arne L. O crescimento do trabalho precário: um desafio global. Revista Brasileira de Ciências Sociais, v. 24, n. 69, p. 21-30, fev. 2009. 
KREIN, José Dari; PRONI, Marcelo W. Economia informal: aspectos conceituais e teóricos. Brasília: OIT, 2010. (Série Trabalho Decente no Brasil, n. 1).

NACIONES UNIDAS. Objetivos de desarrollo del milenio, Informe 2010. Nueva York, EUA: Naciones Unidas, DESA, 2010.

OCAMPO, José Antonio. Employment and the UN Development Agenda. In: OCAMPO, J. A.; JOMO K. S. (Ed.). Towards full and decent employment. New York, USA: Zed Books; United Nations Publications, 2007.

OIT. Trabajo decente. Memoria del Director General. Conferencia Internacional del Trabajo, 87ª Reunión. Ginebra: Oficina Internacional del Trabajo, jun. 1999.

Panorama laboral 2001: América Latina y el Caribe. Lima: Oficina Regional para las Américas y el Caribe, 2001.

Generando trabajo decente en el Mercosur. Empleo y estrategia de crecimiento: el enfoque de la OIT. Buenos Aires: OIT, marzo de 2004.

Trabalho decente nas Américas: uma agenda hemisférica, 2006-2015. Informe do Diretor Geral. XVI Reunião Regional Americana. Brasília: Organização Internacional do Trabalho, maio, 2006.

Declaración de la OIT sobre la justicia social para una globalización equitativa. Conferencia Internacional del Trabajo, 97ª Reunión, Ginebra, 10 jun. 2008.

Panorama laboral 2008: América Latina y el Caribe. Lima: Oficina Regional para las Américas y el Caribe, 2009a.

Perfil do trabalho decente no Brasil. Brasília. Genebra: Escritório da Organização Internacional do Trabalho, 2009b.

Tendencias mundiales del empleo de 2011: el desafío de la recuperación del empleo. Ginebra: Oficina Internacional del Trabajo, 2011a.

Brasil, uma estratégia inovadora alavancada pela renda. Genebra: Organização Internacional do Trabalho, Instituto Internacional de Estudos do Trabalho, $2011 \mathrm{~b}$.

POCHMANN, Marcio. Políticas sociais e padrão de mudanças no Brasil durante o governo Lula. Ser Social, Brasília, v. 13, n. 38, p. 12-40, jan./jun. 2011.

POLLERT, Anna; CHARLWOOD, Andy. The vulnerable worker in Britain and problems at work. Work, Employment and Society, London, v. 23, n. 2, p. 343-362, Jun. 2009.

PRONI, Marcelo W.; ROCHA, Thaíssa T. A OIT e a promoção do trabalho decente no Brasil. Revista da ABET, Associação Brasileira de Estudos do Trabalho, vol. IX, n. 1, p. 11 31, jan./jun. 2010.

QUADROS, Waldir. Em 2009 a heterodoxia afastou a crise social. Campinas: IE/Unicamp, mar. 2011. (Texto para Discussão, n. 189).

RODGERS, Gerry. Precarious employment in Western Europe: the state of the debate. In: RODGERS, G.; RODGERS, J. (Ed.). Precarious jobs in labour market regulation: the 
growth of atypical employment in Western Europe. Geneva: International Institute for Labour Studies, 1989.

SAUNDERS, Ron. Defining vulnerability in the labour market. Ottawa: Canadian Policy Research Networks, Nov. 2003. (Vulnerable Work Series, n. 1).

SOMAVIA, Juan. Discurso de Juan Somavia en la 17 Reunión Regional Americana. Organización Internacional del Trabajo. Santiago de Chile, 14 dic. 2010. Disponible en: http://oit.org.pe/index.php?option=com content\&view=article\&id=2426:discurso-de-juansomavia-en-la-17-reunion-regional-americana\&catid=117:ultimas-noticias\&Itemid=1305.

TOKMAN, Víctor. Flexigurança com informalidade: opções e restrições. In: WELLER, J. (Ed.). O novo cenário laboral latino-americano: regulação, proteção e políticas ativas nos mercados de trabalho. Santiago do Chile: Nações Unidas, Cepal; Ministry of Foreign Affairs of Denmark, 2009.

UNITED KINGDOM. DTI. Success at work: protecting vulnerable workers, supporting good employers. A policy statement for this Parliament. London: Department of Trade and Industry, 2006.

WELLER, Jünger. (Ed.). O novo cenário laboral latino-americano: regulação, proteção e políticas ativas nos mercados de trabalho. Santiago do Chile: Nações Unidas, Cepal; Ministry of Foreign Affairs of Denmark, 2009. 